\title{
Ethics in epidemiology and public health II. Applied terms
}

\section{R E McKeown, D L Weed}

J Epidemiol Community Health 2002;56:739-741

This is the second part of a two part glossary on terms used in public health ethics. This glossary focuses on terms related to the professional practice of epidemiology and public health.
See end of article for authors' affiliations

Professor R E McKeown, Department of Epidemiology and Biostatistics, Norman J Arnold School of Public Health, University of South Carolina, Columbia, SC 29208 USA;

rmckeown@gwm.sc.edu n the first part of this two part glossary, we introduced fundamental-so called "technical" - terms used in both clinical bioethics and public health ethics. ${ }^{1}$ Though there may be variations in emphasis or connotation across different disciplines, we believe the definitions provided there can be understood by people working from a broad range of perspectives. In the present installment we turn our attention to terms more closely related to the professional practice of epidemiology and public health, though with clear overlap in other areas. In her earlier contribution to this series dealing with social epidemiology, Nancy Krieger ${ }^{2}$ tackled several definitions that are central to our task, including social justice, social equity, and human rights. Our assignment having thus been made easier, we limit the current list to terms not previously defined.

Our purpose is, first, to provide a set of brief, coherent definitions that can be used in discussing the ethical justification of one action over another, and, second, to stimulate the discussion of ethical concepts within the discipline. Discussion and debate about the application of these concepts to our professional practice will surely be a positive step in increasing our sensitivity to ethical issues and our skill in ethical analysis.

\section{ADVOCACY}

Literally, "coming to the aid of others." Refers to the process of supporting legal, policy, or scientific positions, decisions, and arguments. For some, public health advocacy has acquired a negative connotation; advocates are perceived as ideological, unyielding, and in conflict with the objectivity required for science based public health decisionmaking. "Thoughtful" advocacy, in which even aggressively held support for decisions can change in response to changes in scientific evidence, has been suggested. ${ }^{3}{ }^{4}$

\section{BENEFITS AND RISKS}

Benefits are goods or outcomes a person or community values; risks are harms or injury. The relative weight of benefits and risks may vary according to the perspective of those involved. For professionals, clarification of benefits and risks should include the probability of the outcome and its extent, severity, magnitude, or degree in terms comprehensible to those affected. Minimal risk is typically defined as risk that does not exceed those encountered as part of daily life or in routine examinations. ${ }^{5-7}$

\section{COERCION}

Manipulation, excessive pressure or influence to force or entice a person to enrol in a research project or a public health programme (for example, screening, immunisation). May take the form of excessive incentives, social pressure, use of authority figures, or playing upon perceived vulnerability of the person..$^{8-11}$ (See informed consent.)

\section{COMMON GOOD}

Shared values or benefits deemed to be good, either explicitly or tacitly, for individuals and for society. Definition is critical for public health, but may be difficult to discern or achieve consensus. For epidemiological and public health practice, elements of the larger public good include health itself as social value and the broader value of "assuring conditions under which people can be healthy". The common good is often cited to balance claims of the individual. ${ }^{1012}$

\section{CONFIDENTIALITY}

(See also: Privacy)

Refers to information, often of a private or sensitive nature, which a person has chosen to reveal but which is protected from being revealed to others. Confidential information should not be shared with anyone without consent except when there is a clear ethical justification (for example, approval by a human subjects research review panel), or a legal requirement (for example, regulations to protect children). Research use of identifiable data without consent requires showing importance of the research, minimal risk to those whose information is used, promise of benefit to society, and an obligation to maintain the confidentiality of the information. ${ }^{14-16}$

\section{EQUIPOISE}

A state of uncertainty on the part of an investigator or a community of investigators regarding the relative merits of interventions. From middle French terms meaning equal weight. Equipoise is an ethical problem when a professional believes one study intervention is superior. Randomly assigning groups of persons to the alternative intervention thus conflicts with an obligation to do the best for the patient or community. "Community" or "clinical" equipoise-collective 
professional uncertainty-may be invoked to make trial participation ethically acceptable. ${ }^{17}$

\section{PROFESSIONAL ETHICS GUIDELINES}

Documents prepared by members of a public health discipline or representative professional society (for example, American College of Epidemiology or the Public Health Leadership Society) containing core values, duties (obligations), and virtues of the profession, sometimes in the form of general principles. Distinguished from guidelines for good scientific practices and from rules of professional etiquette, ethics guidelines are consensus documents, providing a foundation for discussion of issues arising in practice such as minimising risks and protecting the welfare of research participants, maintaining public trust, protecting confidentiality and privacy, and obligations to communities. ${ }^{18-20}$

\section{INFORMED CONSENT}

A process in which the risks, benefits, and expectations of an intervention or research project are disclosed to a patient or participant in order for the participant to make an informed decision concerning acceptance or participation. Requires competence, voluntariness (autonomy and lack of coercion), disclosure, comprehension of risks, burdens, and benefits, and consent. Required by regulation and provided for in protocols by those requesting participation or agreement, consent should be viewed, not simply as a form and signature, but as a process engaging the candidate and allowing for "autonomous authorisation". Children may give assent-that is, agree to participate-though they may lack capacity or comprehension for true informed consent. Communities may be asked to give consent for community based research through elected leadership, existing community networks, or ad hoc advisory groups. The question of who speaks for the community is still a subject of discussion. ${ }^{821}$

\section{PRECAUTIONARY PRINCIPLE}

More a decision guideline than an ethical principle. Expresses the conditions for decisions to implement prevention: scientific uncertainty, an acceptable balance of benefits and harms, and responsibility. Implies early intervention. Arose from European environmental movement in the late 1980s, yet increasingly influential for public and global health. ${ }^{22-24}$

\section{PRIVACY}

(See also: Confidentiality)

What a person claims as protected from scrutiny by others unless the person chooses to reveal it. Respect for privacy means that a person should not normally be expected to reveal personal information, conditions, or behaviour unless he/she chooses to reveal it. Violation of privacy requires ethical justification, for example, in cases where it is argued such violations protect others from greater harm. ${ }^{14-16}$

\section{PUBLIC HEALTH}

A constellation of disciplines with a common mission: "The fulfilment of society's interest in assuring conditions in which people can be healthy."12 Definition has two dimensions: public, on a continuum from an aggregate of individuals to people as a whole society to the ecosystem; and health, on a continuum from biomedical through psychosocial wellbeing to broader levels of optimal health and wholeness. ${ }^{25}$ Implies public policy and structural and programmatic efforts as well as services for individuals. A joint function of our understanding of health and disease processes, complex individual and social characteristics and interactions, and society's shared vision and common values.

\section{RESPECT FOR HUMAN DIGNITY}

(See also: Respect for persons in Part $1^{1}$ )
Considered by some the "cardinal principle of modern research ethics" ${ }^{26}$ In addition to respect for autonomy and freedom from coercion, it includes consideration of the human condition, cultural sensitivity by researchers, and protecting persons, not only from physical harm, but also from demeaning or disrespectful actions or situations.

\section{SCIENTIFIC MISCONDUCT}

A class of ethical violations in the conduct of research, generally taken to include falsification, fabrication, fraud, or plagiarism in the proposal, design, implementation, reporting, or review of research, but may also be taken to include violation of the rights and dignity of participants in research, misuse of research funds, and mistreatment of scientific colleagues. ${ }^{27-29}$

\section{VULNERABLE POPULATIONS}

Persons who, by reason of diminished competence or decision making capacity, lack of power or social standing, fragile health, deprivation, or limited access to basic needs including health care, are vulnerable to coercion, abuse, exploitation, discrimination, imposition of unjust burdens of research, and poorer health outcomes. Similar acts may be construed to be coercive in a vulnerable population that would not be in other, well situated populations. Includes children, institutionalised persons, the frail, and those with mental disorder, as well as those on the margins of society. ${ }^{51121263031}$

\section{ACKNOWLEDGEMENT}

The authors thank Nancy Kreiger (University of Toronto) and Gina Etheredge (Tulane University) for helpful suggestions.

\section{Authors' affiliations}

R E McKeown, Department of Epidemiology and Biostatistics, Norman J Arnold School of Public Health, University of South Carolina, Columbia, SC, USA

D L Weed, Office of Preventive Oncology, Division of Cancer

Prevention, National Cancer Institute, Bethesda, MD, USA

\section{REFERENCES}

1 Weed DL, McKeown RE. Ethics in epidemiology and public health I. Technical terms. J Epidemiol Community Health 2001;55:855-7.

2 Krieger N. A glossary for social epidemiology. J Epidemiol Community Health 2001;55:693-700.

3 Weed DL. Science, ethics guidelines, and advocacy in epidemiology. Ann Epidemiol 1994;4:166-71.

4 Krieger N. Questioning epidemiology: objectivity, advocacy, and socially responsible science. Am J Public Health 1999:89:1 151-3.

5 Office for Human Research Protections. Institutional Review Board Guidebook. Washington: US Department of Health and Human Services, 1993.

6 Calman K. Cancer: science and society and the communication of risk. BM 1996;313:799-802.

7 Calman K, Royston G. Personal paper: Risk language and dialects. BM 1997; 315:939-42

8 Beauchamp TL. Informed consent. In: Veatch RM, ed. Medical ethics 2nd edn. Sudbury MA: Jones and Bartlett Publishers, 1997: 185-208.

9 The Nuremberg Code. In: Veatch RM, ed. Medical ethics. 2nd ed. Sudbury, MA: Jones and Bartlett Publishers, 1997:181-82.

10 Pellegrino ED. Autonomy and coercion in disease prevention and health promotion. Theor Med 1984;5:83-91.

11 The National Commission for the Protection of Human Subjects of Biomedical and Behavioral Research. The Belmont Report. Washington, DC: Government Printing Office, 1979.

12 Institute of Medicine, Committee for the Study of the Future of Public Health. The future of public health. Washington, DC: National Academy Press, 1988.

13 Beauchamp DE, Steinbock B. New ethics for the public's health. New York: Oxford University Press, 1999.

14 Gostin L. Health care information and the protection of personal privacy: ethical and legal considerations. Ann Intern Med 1997; 127:683-90.

15 Gostin LO. National health information privacy: regulations under the Health Insurance Portability and Accountability Act. JAMA. 2001;285:3015-21.

16 Gold EB. Confidentiality and privacy protection in epidemiologic research. In: Coughlin SS, Beauchamp TL, eds. Ethics and epidemiology. New York: Oxford University Press, 1996:128-41.

17 Freedman B. Equipoise and the ethics of clinical research. N Engl J Med. 1987;317:141-5. 
18 American College of Epidemiology. American College of Epidemiology Ethics Guidelines. Ann Epidemiol. 2000;10:487-97.

19 Weed DL, Coughlin SS. New ethics guidelines for epidemiology: background and rationale. Ann Epidemiol 1999;9:277-80.

20 Public Health Leadership Society. Code of ethics for public health. Washington: American Public Health Association, 2002.

21 Glanz K, Rimer BK, Lerman C. Ethical issues in the design and conduct of community-based intervention studies. In: Coughlin SS, Beauchamp TL, eds. Ethics and epidemiology. New York: Oxford University Press, 1996: 156-77.

22 Horton R. The new new public health of risk and radical engagement Lancet 1998;352:251-2.

23 Raffensperger C, Tickner J. Protecting public health and the environment: implementing the precautionary principle. Washington DC: Island Press, 1999.

24 Kriegel D, Tickner J. Reenergizing public health through precaution. Am J Public Health 2001;91:1351-5.

25 Nijhuis HG, Van der Maesen LG. The philosophical foundations of public health: an invitation to debate. J Epidemiol Public Health 1994;48:1-3.
26 Medical Research Council of Canada. Tri-council policy statement: ethical conduct for research involving humans. Ottawa: Medical Research Council of Canada, Natural Sciences and Engineering Research Council of Canada, Social Sciences and Humanities Research Council of Canada, 1998.

27 Macrina FL. Scientific integrity: an introductory text with cases. Washington, DC: ASM Press, 1995.

28 Soskolne CL, MacFarlane DK. Scientific misconduct in epidemiologic research. In: Coughlin SS Beauchamp TL, eds. Ethics and epidemiology. New York: Oxford University Press, 1996:274-89.

29 Weed DL. Preventing scientific misconduct. Am J Public Health 1998;88:125-9.

30 Thomas SB, Quinn SC. The Tuskegee Syphilis Study, 1932 to 1972: implications for HIV education and AIDS risk education programs in the black community. Am J Public Health 1991;81:1498-505.

31 Tuskegee Syphilis Study Ad Hoc Advisory Panel. Final Report. In: Reiser SJ, Dyck AJ, Curran WJ, eds. Ethics in medicine: historical perspectives and contemporary concerns. Cambridge, MA: MIT Press, 1977:316-21.

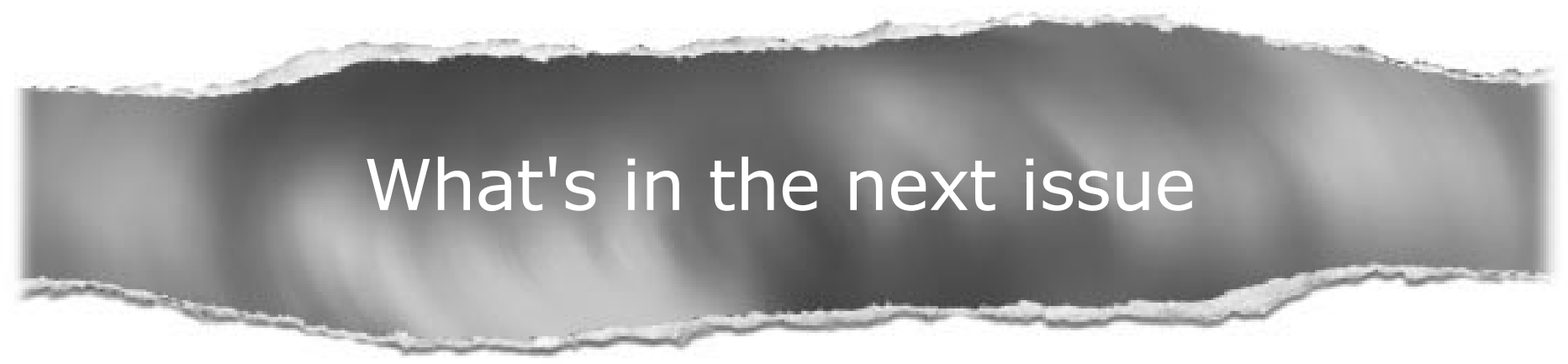

Future content

See which articles have just been accepted for publication and preview the table of contents for the next issue a month before it is published

www.jech.com 